\title{
REVIEW
}

\section{Genetic correlations, tradeoffs and environmental variation}

\author{
CM Sgrò and AA Hoffmann \\ Centre for Environmental Stress and Adaptation Research, La Trobe University, Bundoora, Melbourne 3086, Australia
}

\begin{abstract}
Negative genetic correlations among traits are often used as evidence for tradeoffs that can influence evolutionary trajectories in populations. While there may be evidence for negative correlations within a particular environment, genetic correlations can shift when populations encounter different environmental conditions. Here we review the evidence for these shifts by focusing on experiments that have examined genetic correlations in more than one environment. In many studies, there are significant changes in correlations and
\end{abstract}

these can even switch sign across environments. This raises questions about the validity of deducing genetic constraints from studies in one environment and suggests that the interaction between environmental conditions and the expression of genetic covariation is an important avenue for future work.

Heredity (2004) 93, 241-248. doi:10.1038/sj.hdy.6800532

Published online 28 July 2004

Keywords: genetic correlation; life history; tradeoff; genotype-environment interaction; environmental variation

\section{Introduction}

The last decade has seen an increasing recognition that the environment can have a direct influence on the quantitative genetic parameters underlying life history traits. In particular, attention has focused on whether stressful and unfavourable environmental conditions will have consistent effects on heritable variation, with studies showing that the additive genetic variation for morphological and life history traits can change under some stressful environmental conditions (Hoffmann and Parsons, 1991; Hoffmann and Merilä, 1999; Merilä and Sheldon, 2001).

There is evidence that changes in conditions can influence genetic interactions among traits as well as the genetic variance in traits themselves. Exposure to novel environments (Service and Rose, 1985; Holloway et al, 1990) and inbreeding (Rose, 1984; Whitlock and Fowler, 1999) change the genetic variance of life history traits, and the genetic correlations between them. Novel environments may induce positive correlations among traits because the expression of new genes will break down negative correlations (Rose, 1984), while inbreeding can change genetic correlations in unpredictable and variable ways (Phillips et al, 2001).

Finally, the widespread occurrence of genotypeenvironment interactions has highlighted the potential for changes in genetic interactions with altered environmental conditions. Genotype-environment interactions in life history traits have commonly been found when multiple environments are considered (Vieira et al, 2000; Mackay, 2001; Borevitz et al, 2002) reflecting the fact that genes influencing a trait in one environment may not be

Correspondence: CM Sgrò, Centre for Environmental Stress and Adaptation Research, La Trobe University, Bundoora, Melbourne 3086, Australia.E-mail: c.sgro@latrobe.edu.au

Published online 28 July 2004 important in a different one. Such genotype-environment interactions can result in environment-dependent genetic correlations between life history traits (Service and Rose, 1985; de Jong, 1990; Stearns et al, 1991). Genotypeenvironment interactions are also apparent from the common occurrence of mutations with environmentdependent effects (Kawecki, 1994; Szafraniec et al, 2001), and these in turn may influence genetic correlations between life history traits when environments change.

These empirical studies support much theory developed in the last 20 years or so (Via and Lande, 1985; Clark, 1987; Turelli, 1988; Barton and Turelli, 1989; de Jong, 1990), which suggests that there is little reason to expect genetic parameters to remain constant over a period under constant selection pressures, let alone under conditions where environmental heterogeneity and consequent changes in selection pressures are likely to occur (Via and Lande, 1987). With changes in selection pressures comes the expectation (Price and Schluter, 1991) that heritabilities, additive genetic variances and genetic correlations will also change (Gromko, 1995).

If genetic correlations are commonly dependent on environmental conditions, this has implications for the predictions of evolutionary trajectories and tradeoffs. A fundamental assumption underlying life history theory is that evolution is constrained by universal tradeoffs between traits affecting fitness (Roff, 1992; Stearns, 1992; Reznick et al, 2000). Genetic correlations have been widely used to measure these tradeoffs. Two recent reviews on genetic correlations between life history traits (Roff, 1996, 2000) were largely restricted to studies performed under laboratory environments and most studies support the occurrence of negative genetic correlations. If correlations tend to be consistent in sign and magnitude across most environmental conditions, then there is little need for concern. However, if correlations commonly change, then it 
becomes difficult to make generalizations based on measurements in one environment. Moreover, evolutionary changes may not be constrained in ways indicated by correlations given that organisms in nature often experience rapidly changing conditions within and between generations.

Here we examine evidence for environment-dependent expression of genetic correlations. Despite awareness that genetic parameters can be changed by environmental conditions (and inbreeding), surprisingly few studies have specifically estimated genetic correlations in two or more environments. We consider if shifts in genetic correlations under different laboratory environments are minor, or, alternatively, whether there are larger shifts that may even involve a sign change. Studies on changes in correlations in field or seminatural conditions are also examined, as well as models that can explain shifts in correlations.

\section{Shifts in genetic correlations in laboratory environments}

We focus on studies that have concomitantly tested correlations in more than one environment in the same population, as genetic correlations can differ markedly among populations exposed to different histories of selection (Gromko, 1995). We also only consider studies that have obtained significant correlation estimates in at least one environment, as genetic correlations usually have large standard errors and a low statistical power could prevent the detection of shifts in correlations across environments.

\section{Temperature comparisons}

The effect of temperature on genetic correlations between life history traits has been examined in a number of recent experiments (Windig, 1994; de Jong and Imasheva, 2001; Norry and Loeschcke, 2002). Windig (1994) examined the effect of a range of temperatures (17$28^{\circ} \mathrm{C}$ ) on the genetic correlations between development time, pupal weight and two wing pattern characters, seasonal form and thermal form, in the tropical dry-wet seasonal polyphenic butterfly Bicyclus anynana. Seasonal form is comprised of wing patterns, while thermal form is comprised largely of wing size and colour. Both these wing characters have an impact on fitness: seasonal form is thought to play a role in avoiding predation in the dry and wet seasons, while thermal form in part regulates thermal functions. Because correlations were measured on full-sib data, they can include covariances due to maternal effects and dominance effects as well as the additive genetic covariance. The correlations changed significantly with temperature (Table 1). The correlation between development time and seasonal form changed from being significantly negative at $28^{\circ} \mathrm{C}$ to significantly positive at $20^{\circ} \mathrm{C}$, and that between thermal form and seasonal form changed from being significantly positive at $28^{\circ}$ to significantly negative at $20^{\circ} \mathrm{C}$. Correlations across temperatures for the same trait (ie where the same trait was measured in both environments and the correlations between the estimates compared; see Via and Lande, 1985) also varied. The correlation between development time at 20 and $17^{\circ} \mathrm{C}$ was significantly positive, while the correlation changed sign to become negative between 20 and $23^{\circ} \mathrm{C}$. This indicates that the genetic basis of development time also changed with temperature. All of these changes in correlation with temperature were statistically significant when we tested for differences using the z-test (Zar, 1996). There is therefore clear evidence for environment (temperature)specific genetic correlations between fitness-related traits in B. anynana.

The effects of a heat shock applied at the larval stage on life history associations in Drosophila buzattii were investigated by Krebs and Loeschcke (1999). Trait associations were examined based on the means of 100 isofemale lines. The heat shock was sufficient to alter several of the life history associations, and correlations between the shocked and control treatments for several traits were weak. For instance, adult fecundity and development time were negatively associated, but only in controls and not when development time was scored after a heat shock (Table 1).

Selection experiments have been used to investigate temperature effects on correlations in Drosophila melanogaster. Correlated responses are expected to reflect genetic correlations at least in the initial stages of selection. Norry and Loeschcke (2002) examined correlated responses to selection for cold resistance followed by lifespan truncation selection to test for temperatureinduced changes in trait associations for development time, body size and longevity in this species. They selected adult flies for resistance to $0^{\circ} \mathrm{C}$. After 16 generations of selection, they imposed one generation of truncation selection for longevity on these lines. The lines were tested for divergence in body size, lifespan and development time at 14 and $25^{\circ} \mathrm{C}$. There was evidence of changes in correlations between longevity and body size, and between body size and development time dependent upon the temperature and genetic background of the lines (Table 1). The usually positive association between lifespan and size evident in control lines at $25^{\circ}$ was not evident at $14^{\circ} \mathrm{C}$, and in fact reversed for selected lines tested at $14^{\circ} \mathrm{C}$. An expected tradeoff between development time and body size (see references in Roff, 2000) was evident only when truncation selection on lifespan occurred at $25^{\circ} \mathrm{C}$; this association changed sign when measured at $14^{\circ} \mathrm{C}$. Therefore, positive correlations evident at one temperature and background were reversed at a different temperature and background.

\section{Other changes in conditions}

In addition to temperature, photoperiod may act as an important seasonal cue for life history changes in natural populations of insects. The effects of photoperiod on genetic correlations between life history traits in $D$. melanogaster were studied using the $\mathrm{F}_{3}$ generation of outbred wild-caught flies, reared and tested under two light regimes (Giesel, 1986). A full-sib/half-sib breeding design was used; so genetic correlations should not be complicated by non-additive and maternal effects as in comparisons of isofemale line means. There was a significant positive genetic correlation between age at death and instantaneous birth rate under a long light period, but this correlation was not evident under a short light period. For peak fecundity and instantaneous birth rate, there was also a significant positive correlation 
Table 1 Recent examples of environment-dependent genetic correlations

\begin{tabular}{|c|c|c|c|c|c|c|c|}
\hline \multirow[t]{2}{*}{ Organism } & \multirow[t]{2}{*}{ Traits $^{\mathrm{a}}$} & \multirow[t]{2}{*}{ Methods ${ }^{\mathrm{b}}$} & \multicolumn{2}{|c|}{ Environment ${ }^{c}$} & \multirow[t]{2}{*}{ Stress } & \multirow{2}{*}{$\begin{array}{l}\text { Change in } \mathrm{rg} \\
\text { (genetic correlation) } \\
\text { with environments }{ }^{\mathrm{d}}\end{array}$} & \multirow[t]{2}{*}{ Study } \\
\hline & & & Type & Novel & & & \\
\hline \multicolumn{8}{|l|}{ Laboratory } \\
\hline Bicyclus anynana & DT, PW, SF, TF & $\begin{array}{l}\text { Full-sibs } \\
\text { Lab adapted }\end{array}$ & $17,20,23,28^{\circ} \mathrm{C}$ & $\mathrm{N}$ & $\mathrm{N}$ & Sign, magnitude & Windig (1994) \\
\hline D. buzattii & Fec, DT & Isofemale & Heat shock & & $\mathrm{Y}$ & Sign & $\begin{array}{l}\text { Krebs and } \\
\text { Loeschcke (1999) }\end{array}$ \\
\hline D. melangaster & BS, Long., DT & CRS & $14,25^{\circ} \mathrm{C}$ & & $\mathrm{Y}$ & Sign & $\begin{array}{l}\text { Norry and } \\
\text { Loeschcke (2002) }\end{array}$ \\
\hline D. melanogaster & Fec, IBR, age, death & Full-/half-sib & Photoperiod & $\mathrm{N}$ & $\mathrm{N}$ & Sign, magnitude & Giesel (1986) \\
\hline D. mercatorum & DT, weight & $\begin{array}{l}\text { Isofemale, } \\
\text { isozygous lines, } F_{3} \\
\text { of field adults }\end{array}$ & Resource quality & $\mathrm{N}$ & $\mathrm{Y}$ & Sign, magnitude & $\begin{array}{l}\text { Gebhardt and } \\
\text { Stearns (1988) }\end{array}$ \\
\hline $\begin{array}{l}\text { Callosobruchus } \\
\text { maculatus }\end{array}$ & Fec, Long. & Half-sib & Resource quality & $\mathrm{N}$ & $\mathrm{Y}$ & Sign, magnitude & $\begin{array}{l}\text { Messina and Fry } \\
(2003)\end{array}$ \\
\hline D. melanogaster & Fec, DT, Surv & CRS & $\begin{array}{l}\text { Cadmium } \\
\text { chloride }\end{array}$ & & $\mathrm{Y}$ & Sign & $\begin{array}{l}\text { Shirley and Sibly } \\
\text { (1999) }\end{array}$ \\
\hline D. melanogaster & DT, BS & Model & & & $\mathrm{Y}$ & Sign, magnitude & $\begin{array}{l}\text { de Jong and } \\
\text { Imasheva (2001) }\end{array}$ \\
\hline \multicolumn{8}{|l|}{ Field } \\
\hline Priophorus pallipes & DT, BS & Full-sib & Resource quality & $\mathrm{N}$ & $\mathrm{Y}$ & Sign, magnitude & $\begin{array}{l}\text { Kause and Morin } \\
\text { (2001) }\end{array}$ \\
\hline Daphnia & GR & Clones & Resource quality & $\mathrm{N}$ & $\mathrm{Y}$ & Sign & Tessier et al (2000) \\
\hline $\begin{array}{l}\text { Gryllus } \\
\text { pennsylvanicus }\end{array}$ & DT, Fec, OW & Full-sib & Field, lab & $\mathrm{Y}$ & $\mathrm{N}$ & Sign, magnitude & $\begin{array}{l}\text { Simons and Roff } \\
\text { (1996) }\end{array}$ \\
\hline Impatiens capensis & Rep., Morph. & Genotypes & Shade, density & $\mathrm{N}$ & $\sim \mathrm{Y}$ & Sign, magnitude & $\begin{array}{l}\text { Donohue et al } \\
\text { (2000) }\end{array}$ \\
\hline Ipomoea hederacea & Fitness, tolerance & Inbred lines & Herbivory & $\mathrm{N}$ & Y & Sign & $\begin{array}{l}\text { Stinchcombe } \\
\text { (2002) }\end{array}$ \\
\hline Uta stansburiana & CS, AR & Path analysis & density & $\mathrm{N}$ & Y & Sign & $\begin{array}{l}\text { Svensson et al } \\
\text { (2001) }\end{array}$ \\
\hline Strator limbatus & ES, Fec & Half-sib & resource quality & $\mathrm{N}$ & Y & Sign & $\begin{array}{l}\text { Czesak and Fox } \\
\text { (2003) }\end{array}$ \\
\hline Barley & GY, GM & $\begin{array}{l}\text { Breeding lines } \\
\text { (genotypes) }\end{array}$ & Levels of rainfall & & Y & Sign & $\begin{array}{l}\text { Shakhatreh et al } \\
\text { (2001) }\end{array}$ \\
\hline \multicolumn{8}{|l|}{ Laboratory selection } \\
\hline D. melanogaster & Fec, DT, BS, Long. & CRS & Diff. labs & $\mathrm{Y}$ & $\mathrm{N}$ & Sign & $\begin{array}{l}\text { Ackermann et al } \\
\text { (2001) }\end{array}$ \\
\hline D. melanogaster & Early/late Fec & CRS & $\begin{array}{l}\text { Selection versus } \\
\text { standard }\end{array}$ & $\mathrm{Y}$ & $\mathrm{N}$ & Sign & Leroi et al (1994) \\
\hline
\end{tabular}

aDT, development time; PW, pupal weight; SF, seasonal form; TF, thermal form; BS, body size; Long., longevity; Fec, fecundity; Surv, survival; IBR, instantaneous birth rate; GR, growth rate; OW, ovary weight; Rep., reproductive traits; Morph., morphological traits; CS, clutch size; AR, antibody response; GY, grain yield; GM, grain maturation; ES, egg size.

${ }^{\mathrm{b}} \mathrm{CRS}$, correlated response to selection; genotypes, same genotypes tested in both environments.

'N, no; Y, yes.

aSign, change in the sign of genetic correlation; magnitude, change in the magnitude of genetic correlation.

under a long light period and this disappeared under a short light period. These shifts in correlation coefficients with environmental conditions are likely to be significant given the size of the standard errors associated with the coefficients (Table 1).

Environmental changes that alter levels of nutrition can lead to shifts in genetic correlations between life history traits (Reznick et al, 2000). Gebhardt and Stearns (1988) examined the effects of low and high levels of dietary yeast on the genetic correlation between development time and adult weight in Drosophila mercatorum, by examining the means of flies from crosses between males from isofemale lines and females from two isozygous lines. This crossing scheme results in half-sib families and controls for maternal effects, unlike comparisons of isofemale lines. The genetic correlation between development time and weight changed from being significantly positive in the high-yeast environment to significantly negative in the low-yeast environment, and this difference was significant (by a z-test). Genetic correlations between these traits therefore depended on nutrition levels (Gebhardt and Stearns, 1988) (Table 1).

Changes in genetic correlations with nutrition have also recently been investigated by Messina and Fry (2003) in the seed beetle Callosobruchus maculatus. Using a half-sib design, they found that the genetic correlation between fecundity and longevity changed from being significantly positive in the presence of seeds to 
significantly negative without seeds. This shift in correlation coefficients was therefore significant.

Environment-specific tradeoffs are also likely to occur when genes that influence resistance to environmental stresses have an over-riding effect on traits (Hoffmann and Parsons, 1991). Under stressful conditions, these genes will increase fitness through changing a range of traits. For example, selection for increased resistance to the heavy metal cadmium chloride in D. melanogaster was associated with a sex-linked gene that resulted in increased juvenile survivorship, increased fecundity and decreased developmental time (Shirley and Sibly, 1999). However, under favourable conditions, the same genes may only have a minor impact on variation in these traits, or they may influence a different set of traits. In the study by Shirley and Sibly (1999), the cadmium-resistant lines exhibited a decrease in fecundity, but no change in the other traits (Table 1). Genes that increase performance of a number of fitness traits under stressful conditions may therefore have a different range of effects on traits under favourable conditions and thereby alter genetic correlations among traits.

What emerges from these studies is that once a range of environments are included in an experimental design, negative genetic correlations are often environment dependent. A significant correlation under one set of conditions does not guarantee that the same correlation will exist under a different set of conditions. Evolutionary pathways predicted from genetic correlations will depend on the conditions experienced by organisms across generations. Nevertheless, these laboratory studies have some limitations. While comparisons of isofemale lines are useful for investigating correlations across a range of environments, the interpretation of results from these experiments can be complicated by maternal and non-additive genetic effects. In addition, the range of conditions considered in laboratory experiments have rarely been related to variation in field conditions.

\section{Field and field-relevant studies}

In nature, most organisms are exposed to fluctuating environmental conditions, yet estimates of genetic parameters are often obtained under constant laboratory environments, in an attempt to minimize the environmental component of variance. There has been increasing discussion of the relevance of laboratory-based estimates of genetic variation to natural populations (Weigensberg and Roff, 1996; Sgrò and Hoffmann, 1998; Hoffmann, 2000), and the need to incorporate experimental conditions that have direct relevance to nature.

Many species in nature experience seasonally varying environmental conditions. This variation may play a role in shaping the evolution of life histories by altering the genetic architecture of traits. Kause and Morin (2001) examined the effects of seasonal changes in diet on variation in life history traits in a birch feeding sawfly, Priophorus pallipes, from far north Finland. Experiments were conducted on the $F_{1}$ male offspring of field-caught females, which developed as larvae on three diets differing in quality (high, declining and low). The diets reflected seasonal changes in diet quality under field conditions, since leaves were collected from trees growing in the field throughout the experiment. To further reflect natural conditions, the experiments were conducted at $12{ }^{\circ} \mathrm{C}$ with a photoperiod of $22: 2 \mathrm{~L}: \mathrm{D}$, mimicking the natural conditions of late summer in Lapland. The genetic correlation between body size and development time switched from positive and highly significant on a high-quality diet to negative and highly significant on a low-quality diet (Kause and Morin, 2001) (Table 1), and was not biased by the use of full-sibs (Kause et al, 2001). This switch in sign was statistically significant (by a $z$-test).

Recently, laboratory and field work with Daphnia (Reznick et al, 2000; Tessier et al, 2000) have shown that a tradeoff exists between exploitation of rich versus poor nutritional resources, evident from variation both within and between different species. For instance, clones of Daphnia in field mesocosms that grew relatively rapidly had higher minimum resource requirements (Tessier et al 2000) (Table 1). This association is expected to lead to environment-dependent correlations among life history traits. Both Tessier et al (2000) and Reznick et al (2000) argued that genetic correlations among traits will often be positive when resources are abundant, while negative correlations reflecting tradeoffs may only be apparent when performance/fitness is measured in a resourcepoor environment. Negative correlations require resources to be scarce so that allocation tradeoffs can become expressed.

There is evidence that genetic correlations differ between field and laboratory conditions in the field cricket Gryllus pennsylvanicus (Simons and Roff, 1996) (Table 1). A split-family experiment with the $\mathrm{F}_{1}$ offspring of field-collected adults was used. Members of each family were placed either in the laboratory or in cages in a field enclosure, and their development time, fecundity (ovary weight), ovipositor length and size were measured. Laboratory-based measures of genetic correlations among morphological traits did not differ from those in the variable field environment. However, genetic correlations for life history traits depended on the measurement environment. Most notably, the genetic correlation between fecundity (estimated by ovary weight) and development time changed from nonsignificant in the laboratory to significantly negative in the variable field environment. This change across environments was significant (by a z-test). In addition, the genetic basis of development time differed between the field and laboratory environments, since the across-environment correlation for this trait was not significantly different from zero.

Field experiments with plants have revealed environment-specific genetic correlations for reproductive traits and morphological traits (Table 1). In Impatiens capensis, Donohue et al (2000) manipulated density within two field sites and transplanted plants of several families to each of these sites. A significant negative genetic correlation between meristem allocation to branches and to flowers when plants were grown at a low density in a sunny site became large and significantly positive for the same traits when plants were grown at a low density in the woodland site. Genetic correlations across environments for the same traits also changed across densities. There was a negative genetic correlation for bud production between high- and low-density treatments in the sunny site. This correlation between densities became positive (although marginally non- 
significant) in the woodland site. The switch in sign was significant (by a z-test). An environment-dependent tradeoff has also been shown in the ivy leaf morning glory (Ipomoea hederacea) by Stinchcombe (2002), who studied the costs of tolerance to deer herbivory under field conditions. A negative association between fitness and tolerance to deer herbivory was evident when insect herbivores were present, but not in their absence (Stinchcombe, 2002).

Recent work on the side-blotched lizard Uta stansburiana has provided evidence for condition-dependent genetic correlations. This species exhibits two morphs (orange or yellow throat colour morphs), and Svensson et al (2001) found that a negative association between clutch size and postlaying mass (indicative of condition) was present in the yellow morph but not the orange one (Table 1). Moreover, a negative association between antibody response (immunocompetence) and density of orange neighbours (social environment) was present only in the orange morph. Both these shifts were significant.

In the seed beetle Stator limbatus, the genetic correlation between egg length and fecundity shifted in response to seed type (Czesak and Fox, 2003). Using the $\mathrm{F}_{4}$ generation of field-collected larvae in a half-sib design, two species of seeds collected from the field and photoperiods that mimicked natural conditions, Czesak and Fox (2003) showed that the genetic correlation changed significantly from being zero on the preferred seed to significantly negative on the less preferred seed.

Finally, there is a large body of work in the agricultural literature on genotype-environment interactions for a range of traits under field conditions in both livestock and crops. This literature provides several good examples where there have been switches in genetic correlations across environments. The early literature on such switches was reviewed by Hoffmann and Parsons (1991). For a recent example, Shakhatreh et al (2001) examined performance of barley breeding lines in several locations and showed that the association between grain yield and grain maturation time changed sign between the wettest and driest locations (Table 1).

\section{Other studies}

If the expression of genetic variation in one trait varies with environmental conditions whereas expression in another trait is not environment dependent, this is likely to influence genetic correlations among the two traits in different environments. Selection responses for a trait in a favourable environment often lead to similar changes in a stressful environment, but in many cases these responses are largely environment specific (Hoffmann and Parsons, 1991). Many studies have examined the evolution of host specialization in herbivorous insects by comparing performance across hosts, and cross-host genetic correlations are often positive although they can also be zero or only weakly positive (Joshi and Thompson, 1995). There are also examples of negative genetic correlations in fitness across host plants. For example, in pea aphids, a negative genetic correlation across alfalfa and clover host plants was found for fecundity, longevity and age at first reproduction measured in a field experiment (Via, 1991; Hawthorne and Via, 2001). Similarly, a negative genetic correlation for fecundity across broad bean and nasturtium host plants existed in Aphid fabae (Mackenzie, 1996).

Correlated responses to selection have been widely used to examine genetic constraints in life history evolution. Inconsistencies in correlated responses abound, and these may reflect differences in the environment used for selection (Harshman and Hoffmann, 2000; Ackermann et al, 2001). As correlated responses reflect genetic correlations at least in the initial generations of selection, this suggests differences in trait correlations among environments. As an example, Hillesheim and Stearns (1991) selected on body mass in D. melanogaster in two larval food environments (rich and poor), and found that development time only showed a correlated response to selection on body mass when selection took place under poor conditions.

To test for the environment-specific nature of selection responses in life history traits, Ackermann et al (2001) (Table 1) tested for effects of assay and selection environments in four sets of $D$. melanogaster selection lines from different laboratories under three conditions. One set had been selected for fast or slow development, the second for high or low extrinsic adult mortality, the third for performance at different larval densities, and the fourth for performance at different temperatures. Early fecundity measurements were sensitive to the assay environment, seen as a significant selection regime by assay environment interaction. No significant genotype-environment interactions were found for the other traits; however, for all three traits (development time, longevity, body size), there were cases where measurements in one environment would have led to the conclusion that selection had a significant effect, whereas in other environments no effect of selection would have been apparent (Ackermann et al, 2001).

Other experiments have also indicated that the expression of selection responses depends on environmental conditions, reflecting genotype-by-environment interaction (Clark, 1987; Stearns et al, 1991). For example, Leroi et al (1994) examined a tradeoff between early- and late-life fecundity evident as a correlated response in lines selected for late-life reproductive success, and found that this correlated response was only obvious under some environmental conditions. Similarly, Teotonio et al (2002) showed that larval density conditions influenced correlated changes in selected lines exposed to reverse selection pressures.

\section{Alternatives}

The above studies suggest that genetic correlations among life history traits will often depend on environmental conditions. Thus while there are often consistent patterns among life history traits when measured within one environment that suggest tradeoffs (Roff, 2000), this association may break down when comparing different environments. It is too early to make generalizations about the types of environmental conditions that can lead to changes in correlations. Nevertheless, the environmental dependency of correlations suggests that evolutionary trajectories can be difficult to predict when organisms are exposed to changing conditions. This may influence the impact of trait interactions on evolutionary trajectories. 
One limitation of genetic correlations is that they may not directly reflect tradeoffs. Genetic correlations can be due to pleiotropy or very close linkage, to linkage disequilibrium (which will have little effect on long-term evolution), or to the correlation of both traits of interest with a third, unmeasured trait (Clark, 1987). Genetic correlations that represent genetic constraints between traits need to be maintained by pleiotropic gene action. A number of different approaches have been developed to dissect the genetic mechanism underlying genetic correlations. One of these involves transgenic organisms (Tatar, 1999), which have been used to examine the tradeoff between lifespan and fecundity in D. melanogaster. Using transgenic lines that overexpressed the heatshock protein $h s p 70$, Silbermann and Tatar (2000) showed a connection between this gene and the tradeoff between lifespan and reproduction, providing insight into part of the underlying mechanism. By identifying genes, hypotheses about processes forming tradeoffs can be developed.

Where specific candidate genes cannot be identified, quantitative trait locus (QTL) analysis may prove useful in isolating genes. For instance, Via and Hawthorne (2002) mapped QTLs to examine the genetic mechanism underlying the tradeoff in performance across host plants in pea aphids. Their results suggested that antagonistic pleiotropy was the mechanism by which the tradeoff had evolved, indicating a fundamental tradeoff between performance on these host plants (Via and Hawthorne, 2002).

An alternative to the purely genetic approach of studying life history tradeoffs involves understanding and modelling the physiological mechanisms underlying life history tradeoffs by identifying functional interactions among components of life history traits. For instance, de Jong and Imasheva (2001) developed a biophysical model for understanding the evolution of body size in ectotherms, where size depends on temperature. This model yields development rate and size as complex, nonlinear functions of underlying parameter values (related to temperature). Based on previously published data for D. melanogaster, de Jong and Imasheva (2001) found that patterns of variation in the additive genetic variation for development rate differ from the patterns of genetic variation for body size (Table 1); consequently, the genetic correlation between development rate and body size changes sign repeatedly as a function of temperature, as does the genetic correlation for each trait across temperatures. Roff (2000) also developed a model where the genetic correlation between development time and body size changed in sign and magnitude in an unpredictable way, depending on the magnitude and sign of the genetic variances and covariances for these traits and a third trait (fecundity). The assumption that an increase in body size requires an increase in development time may therefore not hold, particularly under fluctuating conditions.

In a recent review, Zera and Harshman (2001) argued that genetic correlations on their own provide little relevant information on life history tradeoffs without an understanding of the underlying functional (physiological) mechanisms involved. While the primary focus of many physiological studies of tradeoffs has been the differential allocation and acquisition of resources (eg van Noordwijk and de Jong, 1986; de Jong, 1993), Zera and Harshman (2001) pointed out that this may not be the primary physiological cause of life history tradeoffs.

A comprehensive understanding of life history tradeoffs undoubtedly requires information on the underlying functional relationships. However, Via and Hawthorne (2002) have shown that a quantitative genetic approach can provide information on fundamental mechanisms underlying tradeoffs. Ideally, the use of quantitative and molecular genetic techniques, combined with physiological and functional information, will lead to an understanding of how environmental conditions influence underlying life history evolution.

Negative associations between traits may generally occur within an environment (Roff, 1996, 2000). These associations may reflect tradeoffs that have a potentially large role in shaping the evolution of life history traits. But what must be acknowledged is that genetic correlations are environment specific, and the way in which they constrain life history evolution is more complex than evident from experiments in a single environment. Experiments should encompass environmental conditions that organisms are likely to experience in the field. Additional experiments conducted under natural and seminatural conditions, incorporating more than two environments, are needed to determine the prevalence of environment-specific genetic correlations and the extent to which the quantitative genetic approach can provide the information necessary for understanding the direction and extent of evolutionary change under environmentally variable situations. A number of hypotheses could specifically be tested about changes in correlation patterns with environmental conditions. For instance, correlations among life history traits may tend to become more positive with environmental novelty (Service and Rose, 1985) or with increasingly stressful conditions (Hoffmann and Parsons, 1991) and this could be tested by generating novelty or stress gradients (Sgrò and Blows, 2004).

\section{Acknowledgements}

We thank the Australian Research Council for financial support via their fellowship and Special Research Centre schemes.

\section{References}

Ackermann M, Biljsma R, James AC, Partridge L, Zwaan BJ (2001). Effects of assay conditions in life history experiments with Drosophila melanogaster. J Evol Biol 14: 199-209.

Barton NH, Turelli M (1989). Evolutionary quantitative genetics: how little do we know? Annu Rev Genet 23: 337-370.

Borevitz JO, Maloof JN, Lutes J, Dabi T, Redfern JL, Trainer GT et al (2002). Quantitative trait loci controlling light and hormone response in two accessions of Arabidopsis thaliana. Genetics 160: 683-696.

Clark AG (1987). Senescence and the genetic correlation hangup. Am Nat 129: 932-940.

Czesak ME, Fox CW (2003). Evolutionary ecology of egg size and number in a seed beetle: genetic trade-off differs between environments. Evolution 57: 1121-1132.

de Jong G (1990). Quantitative genetics of reaction norms. J Evol Biol 3: 447-468.

de Jong G (1993). Covariances between traits deriving from successive allocations of resources. Funct Ecol 7: 75-83.

de Jong G, Imasheva A (2001). Genetic variance in temperature dependent adult size deriving from physiological 
genetic variation at temperature boundaries. Genetica 110: 195-207.

Donohue K, Pyle E, Messiqua D, Heschel MS, Schmitt J (2000). Density dependence and population differentiation of genetic architecture in Impatiens capensis in natural environments. Evolution 54: 1969-1981.

Gebhardt MD, Stearns SC (1988). Reaction norms for developmental time and weight at eclosion in Drosophila mercatorum. J Evol Biol 1: 335-354.

Giesel JT (1986). Genetic correlation structure of life history variables in outbred, wild Drosophila melanogaster: effects of photoperiod regime. Am Nat 128: 593-603.

Gromko MH (1995). Unpredictability of correlated response to selection: pleiotropy and sampling interact. Evolution 49: 685-693.

Harshman LG, Hoffmann AA (2000). Laboratory selection experiments using Drosophila: what do they really tell us? Trends Ecol Evol 15: 32-36.

Hawthorne DJ, Via S (2001). Genetic linkage of ecological specialisation and reproductive isolation in pea aphids. Nature 412: 904-907.

Hillesheim E, Stearns SC (1991). The responses of Drosophila melanogaster to artificial selection on body weight and its phenotypic plasticity in two larval food environments. Evolution 45: 1909-1923.

Hoffmann AA (2000). Laboratory and field heritabilities: some lessons from Drosophila. In: Mousseau TA (ed) Adaptive Genetic Variation in the Wild, Oxford University Press: New York. pp 200-218.

Hoffmann AA, Merilä J (1999). Heritable variation and evolution under favourable and unfavourable conditions. Trends Ecol Evol 14: 96-101.

Hoffmann AA, Parsons PA (1991). Evolutionary Genetics and Environmental Stress, Oxford University Press: Oxford.

Holloway GJ, Povey SR, Sibly RM (1990). The effect of new environment on adapted genetic architecture. Heredity 64: 323-330.

Joshi A, Thompson JN (1995). Trade-offs and the evolution of host specialisation. Evol Ecol 9: 82-92.

Kause A, Morin J (2001). Seasonality and genetic architecture of development time and body size of the birch feeding sawfly, Priophorus pallipes. Genet Res 78: 31-40.

Kause A, Saloniemi I, Morin J, Haukioja E, Hanhimaki S, Ruohomaki K (2001). Seasonally varying diet quality and the quantitative genetics of development time and body size in birch feeding insects. Evolution 55: 1992-2001.

Kawecki TJ (1994). Accumulation of deleterious mutations and the evolutionary cost of being a generalist. Am Nat 144: 833-838.

Krebs RA, Loeschcke V (1999). A genetic analysis of the relationship between life-history variation and heat-shock tolerance in Drosophila buzattii. Heredity 83: 46-53.

Leroi AM, Chippindale AK, Rose MR (1994). Long-term laboratory evolution of a genetic life-history trade-off in Drosophila melanogaster. 1. The role of genotype-environment interaction. Evolution 48: 1244-1257.

Mackay TFC (2001). The genetic architecture of quantitative traits. Annu Rev Genet 35: 303-339.

Mackenzie A (1996). A trade-off for host plant utilization in the black bean aphid, Aphis fabae. Evolution 50: 155-162.

Merilä J, Sheldon BC (2001). Avian quantitative genetics. Curr Ornithol 16: 179-255.

Messina FJ, Fry JD (2003). Environment-dependent reversal of a life history trade-off in the seed beetle Callosobruchus maculatus. J Evol Biol 16: 501-509.

Norry FM, Loeschcke V (2002). Temperature-induced shifts in associations of longevity with body size in Drosophila melanogaster. Evolution 56: 299-306.

Phillips PC, Whitlock MC, Fowler K (2001). Inbreeding changes the shape of the genetic covariance matrix in Drosophila melanogaster. Genetics 158: 1137-1145.
Price T, Schluter D (1991). On the low heritability of life history traits. Evolution 45: 853-861.

Reznick D, Nunney L, Tessier A (2000). Big houses, big cars, superfleas and the cost of reproduction. Trends Ecol Evol 15: 421-425.

Roff DA (1992). The Evolution of Life Histories, Chapman and Hall: London.

Roff DA (1996). The evolution of genetic correlations: an analysis of patterns. Evolution 50: 1392-1403.

Roff DA (2000). Trade-offs between growth and reproduction: an analysis of the quantitative genetic evidence. J Evol Biol 13 434-445.

Rose MR (1984). Genetic covariation in Drosophila life history: untangling the data. Am Nat 123: 565-569.

Service PM, Rose MR (1985). Genetic covariation among life history components: the effect of novel environments. Evolution 39: 943-945.

Sgrò CM, Blows MN (2004). The genetic covariance among clinal environment after adaptation to an environmental gradient in Drosophila serrata. Genetics (in press).

Sgrò CM, Hoffmann AA (1998). Heritable variation for fecundity in field-collected Drosophila melanogaster and their offspring reared under different environmental temperatures. Evolution 52: 134-143.

Shakhatreh Y, Kafawin O, Ceccarelli S, Saoub H (2001) Selection of barley lines for drought tolerance in low-rainfall areas. J Agron Crop Sci 186: 119-127.

Shirley MD, Sibly RM (1999). Genetic basis of a betweenenvironment trade-off involving resistance to cadmium in Drosophila melanogaster. Evolution 53: 826-836.

Silbermann R, Tatar M (2000). Reproductive costs of heat shock protein in transgenic Drosophila melanogaster. Evolution $\mathbf{5 4}$ 2038-2045.

Simons AM, Roff DA (1996). The effect of a variable environment on the genetic correlation structure in a field cricket. Evolution 50: 267-275.

Stearns SC (1992). The Evolution of Life Histories, Oxford University Press: Oxford.

Stearns SC, de Jong G, Newman B (1991). The effects of plasticity on genetic correlations. Trends Ecol Evol 6: 20-26.

Stinchcombe JR (2002). Environmental dependency in the expression of costs of tolerance to deer herbivory. Evolution 56: 1063-1067.

Svensson E, Sinervo B, Comendant T (2001). Condition, genotype-environment interaction and correlational selection in lizard life history morphs. Evolution 55: 2053-2069.

Szafraniec K, Borts R, Korona R (2001). Environmental stress and mutational load in diploid strains of the yeast Saccharomyces cerevisiae. Proc Nat Acad Sci USA 98: 1107-1112.

Tatar M (1999). Transgenes in the analysis of lifespan and fitness. Am Nat 154: S67-S81.

Teotonio H, Matos M, Rose MR (2002). Reverse evolution of fitness in Drosophila melanogaster. J Evol Biol 15: 608-617.

Tessier A, Leibold MA, Tsao J (2000). A fundamental trade-off in resource exploitation by Daphnia and consequences to plankton communities. Ecology 81: 826-841.

Turelli M (1988). Phenotypic evolution, constant covariances and the maintenance of additive genetic variance. Evolution 42: 1342-1347.

van Noordwijk AJ, de Jong G (1986). Acquisition and allocation of resources: their influence on variation in life history tactics. Am Nat 128: 137-142.

Via S (1991). The genetic structure of host plant adaptation in a spatial patchwork: demographic variability among reciprocally transplanted pea aphid clones. Evolution 45: 827-852.

Via S, Hawthorne DJ (2002). The genetic architecture of ecological specialisation: correlated gene effects on host use and habitat choice in pea aphids. Am Nat 159: S76-S88.

Via S, Lande R (1985). Genotype-environment interaction and the evolution of phenotypic plasticity. Evolution 39: 505-522. 
Via S, Lande R (1987). Evolution of genetic variability in a spatially heterogeneous environment: effects of genotypeenvironment interaction. Genet Res 49: 147-156.

Vieira C, Pasyukova EG, Zeng ZB, Hackett JB, Lyman RF, Mackay TFC (2000). Genotype-environment interaction for quantitative trait loci affecting life span in Drosophila melanogaster. Genetics 154: 213-227.

Weigensberg I, Roff DA (1996). Natural heritabilities: can they be reliably estimated in the laboratory? Evolution 50: 2149-2157.
Whitlock MC, Fowler K (1999). The changes in genetic and environmental variance with inbreeding in Drosophila melanogaster. Genetics 152: 345-353.

Windig JJ (1994). Genetic correlations and reaction norms in wing pattern in tropical butterfly Bicyclus anynana. Heredity 73: 459-470.

Zar JH (1996). Biostatistical Analysis, Prentice-Hall Inc.: New Jersey.

Zera AJ, Harshman LG (2001). The physiology of life history trade offs in animals. Ann Rev Ecol Syst 32: 95-126. 